\title{
Corneal Hydrops in Pellucid Marginal Degeneration: A Case Series
}

\author{
Vipul Bhandari Sri Ganesh \\ Department of Cornea, Nethradhama Eye Hospital, Bangalore, India
}

\section{Key Words}

Pellucid marginal degeneration · Hydrops $\cdot$ Corneal perforation

\begin{abstract}
Purpose: To report an unusual presentation of pellucid marginal degeneration (PMD) and its management by using air injection and tension sutures. Case Report: We report 2 cases with a history of acute pain and loss of vision. Examination revealed hydrops at the 6-9 o'clock meridian with Descemet's membrane detachment and tear at the same area and advanced PMD in the other eye. Discussion: Air injection with suturing to treat the hydrops in PMD and crescentic excision with lamellar grafting instead of lamellar keratoplasty lead to better results than conservative management. Conclusion: Corneal hydrops and perforation in patients with PMD is a rare presentation and can be managed by tension sutures and air injection.

(c) 2015 S. Karger AG, Basel
\end{abstract}

\section{Introduction}

Pellucid marginal degeneration (PMD) is characterized by nonulcerative, noninflammatory, clear thinning of the inferior portion of the peripheral cornea $[1,2]$. The hallmark of this disorder includes an area of corneal protrusion above the point of maximal thinning rather than within the area of maximal thinning as with keratoconus. A 1- to 2-mm zone of uninvolved normal cornea separates the region of thinning from the peripheral limbus. A characteristic pattern of inferior corneal steepening and subsequent against-the-rule astigmatism is found on corneal topography. Atypical presentations of PMD have been reported in the literature. The various presentations include superior PMD or PMD in association with keratoconus or keratoglobus [3]. Acute hydrops is the development of marked edema of the 
Bhandari and Ganesh: Corneal Hydrops in Pellucid Marginal Degeneration: A Case Series

corneal stroma and epithelium following a break in Descemet's membrane (DM). It is well known to occur in keratoconus and has also been reported in other corneal ectasia, especially in PMD and keratoglobus [4,5]. This is a rare complication of keratoconus and is even rarer in PMD [6-11]. Herein we report an unusual case series of PMD with spontaneous corneal hydrops and describe its management.

\section{Case Reports}

Case 1

A 48-year-old man presented with symptoms of pain, photophobia, tearing and severe visual loss in his left eye of 4 days' duration. He was in good general health and had no history of systemic disorders, seasonal allergy or recent ocular trauma. He reported a gradual decrease in vision over the past 10 years. Upon presentation, his best corrected visual acuity (BCVA) was $1.77 \operatorname{logMAR}$ in the left eye and $0.48 \operatorname{logMAR}$ in the right eye. Slit-lamp biomicroscopy in the left eye revealed a dense central and nasal corneal edema with DM detachment and tear (fig. 1a, b). Anterior segment optical coherence tomography (AS-OCT) was performed (fig. 2). In the right eye, the cornea was clear except for a crescent-shaped area of subepithelial scarring approximately $3 \mathrm{~mm}$ in length superior to the inferior limbus. Neither Fleischer ring nor Vogt's striae were noted. Orbscan (Bausch and Lomb, Germany) and Pentacam (Oculus, Germany) imaging was performed in the right eye (fig. 3). We performed an air injection with tension sutures to reattach the DM in the left eye (fig. 4a, b). In the right eye, we performed a lamellar crescentic excision and placed an undersized graft with tight sutures with accelerated collagen cross-linking (C3R). The BCVA improved to 0.18 logMAR with a correction of $-1.0 \mathrm{DS} /-2.0 \mathrm{DC} * 130$, N6 with near add of $+1.50 \mathrm{D}$ in the left eye and 0.1 logMAR with a correction of +1.0 DS/-3.0 DC*70, N6 with a near add of +1.50 D in the right eye at the end of 6 months after complete suture removal. AS-OCT showed a decrease in corneal thickness and DM attachment in the left eye (fig. 5). No complications were noted in the follow-up period. Orbscan and Pentacam images showed no signs of progression during the follow-up period of 16 months. (fig. 6a, b).

Case 2

A 35-year-old man presented with symptoms of pain, photophobia, tearing and severe visual loss in his right eye of 4 days' duration. He was in good general health and had no history of systemic disorders, seasonal allergy or recent ocular trauma. He reported a gradual decrease in vision over the past 10 years. Upon presentation, his BCVA was 2.3 logMAR in the right eye and $0.60 \operatorname{logMAR}$ in the left eye. Slit-lamp biomicroscopy in the right eye revealed a dense central and nasal corneal edema with DM detachment and tear. AS-OCT was performed. In the left eye, the cornea was clear except for a crescent-shaped area of subepithelial scarring approximately $3 \mathrm{~mm}$ in length superior to the inferior limbus. Neither Fleischer ring nor Vogt's striae were noted. Orbscan and Pentacam imaging was performed in the left eye. Corneal thickness was $462 \mu \mathrm{m}$ in the inferior area near the limbus. We performed an air injection with tension sutures to reattach the DM in the right eye. In the left eye, we performed a lamellar crescentic excision and placed an undersized graft with tight sutures with accelerated collagen cross-linking (C3R) (fig. 7). The BCVA improved to 0.18 $\operatorname{logMAR}$ with a correction of $-1.0 \mathrm{DS} /-2.0 \mathrm{DC} * 110$, N6 in the right eye and 0.1 logMAR with a correction of +1.0 DS/-3.25 DC*60, N6 in the left eye at the end of 6 months after complete suture removal. AS-OCT showed a decrease in corneal thickness and DM attachment in the 
Bhandari and Ganesh: Corneal Hydrops in Pellucid Marginal Degeneration: A Case Series

right eye. No complications were noted in the follow-up period. Orbscan and Pentacam images showed no signs of progression during the follow-up period.

\section{Discussion}

Progressive corneal ectasia in keratoconus and PMD can, in rare cases, lead to DM rupture causing acute hydrops [8], which has been shown to respond favorably to conservative medical management $[7,10]$. Acute hydrops has been associated in the past with chronic allergy [4]. Corneal perforation in this setting is exceedingly rare $[6-9,11]$ and usually occurs secondary to trauma, eye rubbing and very rarely spontaneously $[4,10,12]$. Tuft et al. [4] found evidence suggesting that flattening of the cornea may occur after spontaneous resolution of hydrops. Our patient developed symptoms of acute hydrops in the left eye without any evidence of trauma, eye rubbing or allergic eye diseases. It was not possible to distinguish between keratoconus and PMD in the involved eye, but the fellow eye demonstrated characteristic features of PMD. The development of signs and symptoms of PMD in the fifth decade of life and rapid progression to spontaneous perforation within 1 year during the next decade is unusual for PMD. Jeng et al. [9] reported the first case of hydrops and perforation in both eyes in a patient with PMD. In their report, the second eye developed hydrops and perforation 20 months after initial presentation. Dantas and Nishiwaki-Dantas [12] reported another patient who developed hydrops and perforation in the fellow eye 12 months after a similar presentation in the first eye, confirming that patients with hydrops and perforation in one eye are at risk for a similar event in the other eye. Acute corneal hydrops has been estimated to occur in the setting of keratoconus and PMD in 2.5-6\% of cases $[10,13]$. Lucarelli et al. [6] were the first to report spontaneous perforation in PMD. Jeng et al. [9] published the first report of sequential bilateral spontaneous corneal perforation occurring 20 months apart between the eyes, after the patient's first eye was reported by Aldave et al. [11]. Forooghian et al. [14] reported the second case of sequential spontaneous corneal perforation in a patient with PMD, with corneal perforation occurring 1 year apart between the affected eyes. In cases of spontaneous corneal perforation, most cases are ultimately treated with either a penetrating keratoplasty or lamellar keratoplasty after initial attempts at glue application and therapeutic contact lens placement. In the present case series, we performed air injection with suturing to treat the hydrops in PMD and a crescentic excision with lamellar grafting instead of lamellar keratoplasty similar to C-shaped lamellar keratoplasty using multiple trephines of different sizes, with deliberate undersizing of the donor graft for a controlled compressive effect first described by Cheng et al. [15]. C3R and C3R combined with phototherapeutic keratectomy is a known treatment modality for early PMD. In the present case series, since both cases had advanced PMD with hydrops and the fellow eye was also showing advanced PMD, we combined lamellar crescentic excision with collagen cross-linking. The criteria for crescentic lamellar grafting are advanced PMD and advanced PMD with hydrops in the other eye. The role of C3R is to supplement the flattening caused by the tension suturing, even though the diseased tissue is removed. This helps in stabilizing the cornea. Air injection with suturing to treat the hydrops in PMD and crescentic excision with lamellar grafting instead of lamellar keratoplasty lead to better results than conservative management. 
Bhandari and Ganesh: Corneal Hydrops in Pellucid Marginal Degeneration: A Case Series

\section{Statement of Ethics}

Informed consent and approval from the Ethics Committee was obtained.

\section{Disclosure Statement}

The authors declare no conflicts of interest.

\section{References}

1 Krachmer JH: Pellucid marginal corneal degeneration. Arch Ophthalmol 1978;96:1217-1221.

-2 Krachmer JH, Feder RS, Belin MW: Keratoconus and related noninflammatory corneal thinning disorders. Surv Ophthalmol 1984;28:293-322.

-3 Bower KS, Dhaliwal DK, Barnhorst DA Jr, Warnicke J: Pellucid marginal degeneration with superior corneal thinning. Cornea 1997;16:483-485.

-4 Tuft SJ, Gregory WM, Buckley RJ: Acute corneal hydrops in keratoconus. Ophthlalmology 1994;101:17381744

5 Carter JB, Jones DB, Wilhlemus KR: Actute hydrops in pellucid marginal corneal degeneration. Am J Ophthalmol 1989;107:167-170.

-6 Lucarelli MJ, Gendelman DS, Talamo JH: Hydrops and spontaneous perforation in pellucid marginal corneal degeneration. Cornea 1997;16:232-234.

7 Orlin SE, Sulewski ME: Spontaneous corneal perforation in pellucid marginal degeneration. CLAO J 1998;24:186-187.

-8 Akpek EK, Altan-Yaycioglu R, Gottsch JD, Stark WJ: Spontaneous corneal perforation in a patient with unusual unilateral pellucid marginal degeneration. J Cataract Refract Surg 2001;27:1698-1700.

-9 Jeng BH, Aldave AJ, McLeod SD: Spontaneous corneal hydrops and perforation in both eyes of a patient with pellucid marginal degeneration. Cornea 2003;22:705-706.

10 Grewal S, Laibson PR, Cohen EJ, Rapuano CJ: Acute hydrops in the corneal ectasias: associated factors and outcomes. Trans Am Ophthalmol Soc 1999;97:187-198, discussion 198-203.

-11 Aldave AJ, Mabon M, Hollander DA, McLeod SD, Spencer WH, Abbott RL: Spontaneous corneal hydrops and perforation in keratoconus and pellucid marginal degeneration. Cornea 2003;22:169-174.

$\$ 12$ Dantas PE, Nishiwaki-Dantas MC: Spontaneous bilateral corneal perforation of acute hydrops in keratoconus. Eye Contact Lens 2004;30:40-41.

-13 Kayazawa F, Nishimura K, Kodama Y, et al: Keratoconus with pellucid marginal degeneration. Arch Ophthalmol 1984;102:895-896.

14 Forooghian F, Assaad D, Dixon W: Successful conservative management of hydrops with perforation in pellucid marginal degeneration. Can J Ophthalmol 2006;41:74-77.

15 Cheng CL, Theng JT, Tan DT: Compressive C-shaped lamellar keratoplasty: a surgical alternative for the management of severe astigmatism from peripheral corneal degeneration. Ophthalmology 2005;112:425430. 
Case Reports in

Ophthalmology

\begin{tabular}{l|l}
\hline \multicolumn{2}{l}{ Case Rep Ophthalmol 2015;6:191-199 } \\
\hline DOI: 10.1159/000434623 & $\begin{array}{l}\text { ○ 2015 S. Karger AG, Basel } \\
\text { www.karger.com/cop }\end{array}$ \\
\hline
\end{tabular}

Bhandari and Ganesh: Corneal Hydrops in Pellucid Marginal Degeneration: A Case Series
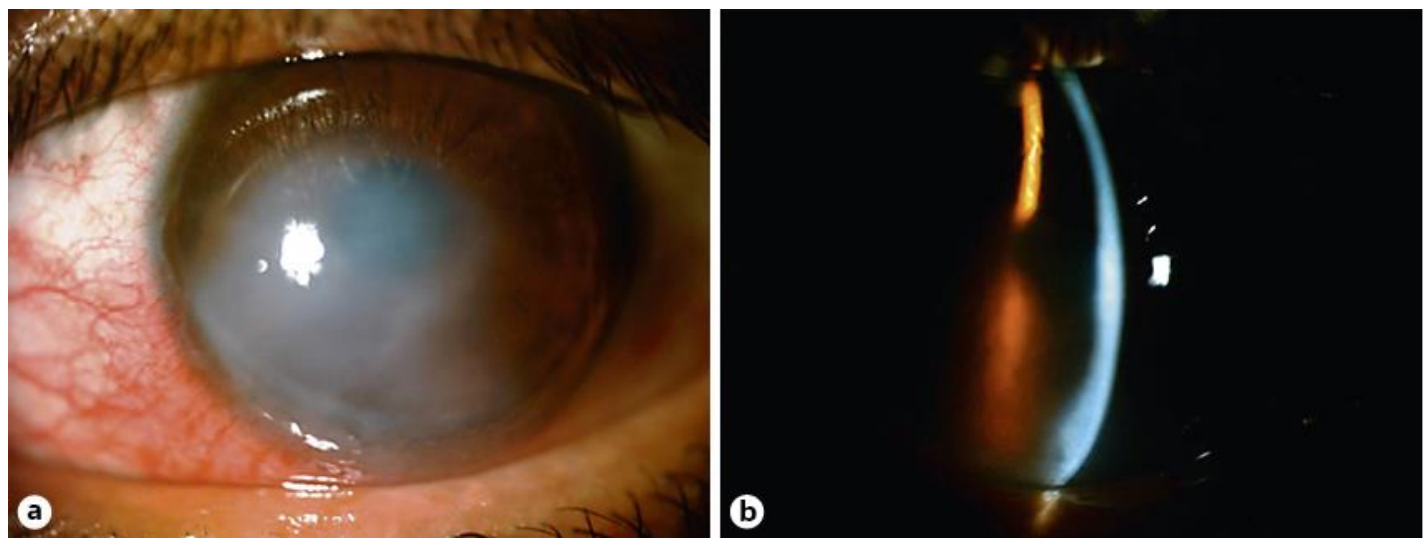

Fig. 1. a DM detachment. b DM tear.



Fig. 2. AS-OCT showing DM detachment and corneal pachymetry. 


\section{Case Reports in \\ Ophthalmology}

\begin{tabular}{l|l}
\hline \multicolumn{2}{l}{ Case Rep Ophthalmol 2015;6:191-199 } \\
\hline DOI: 10.1159/000434623 & $\begin{array}{l}\text { ○ 2015 S. Karger AG, Basel } \\
\text { www.karger.com/cop }\end{array}$ \\
\hline
\end{tabular}

Bhandari and Ganesh: Corneal Hydrops in Pellucid Marginal Degeneration: A Case Series

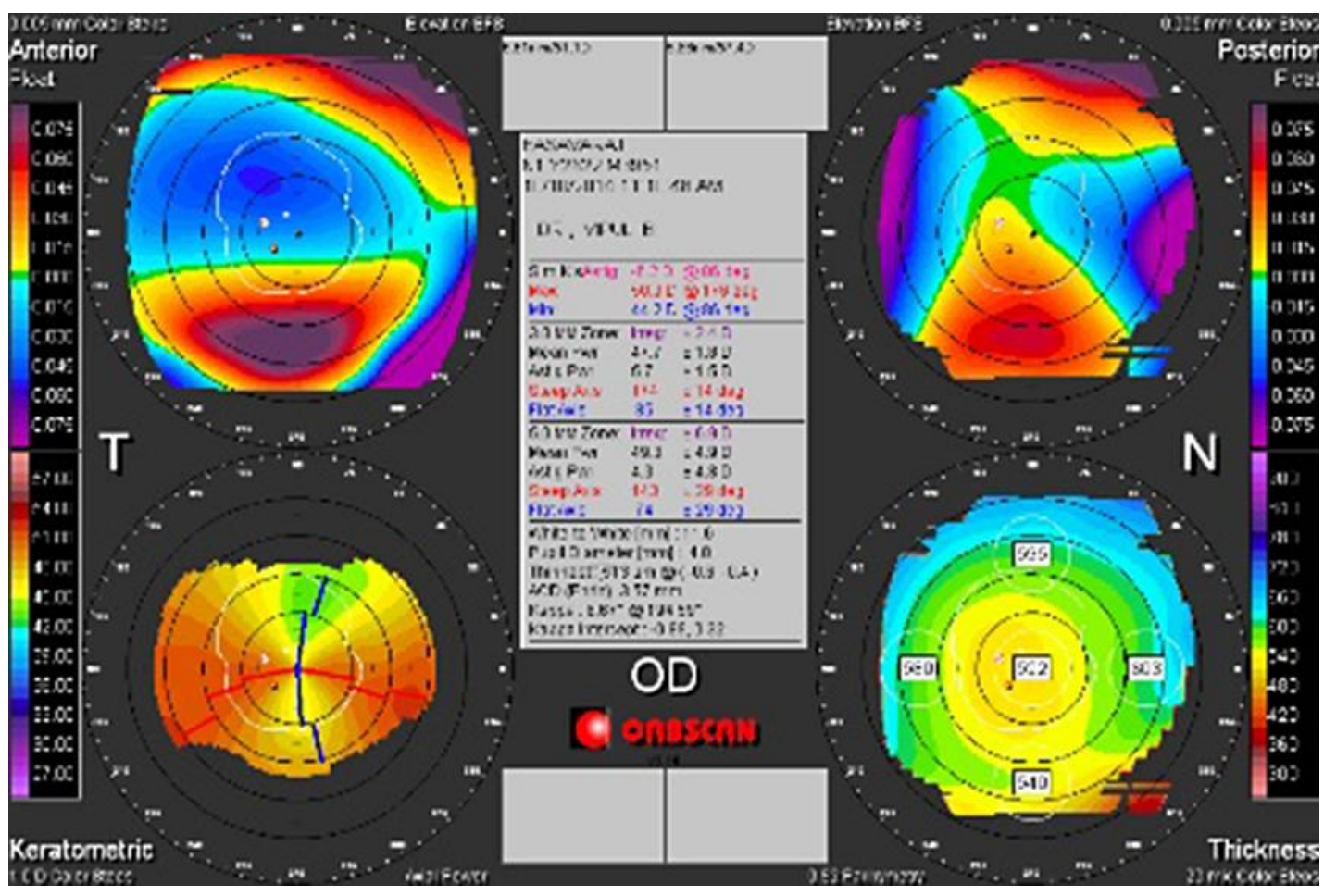

Fig. 3. Orbscan images showing PMD.



Fig. 4. a After air injection and suturing. b Slit-lamp section showing DM attachment. 
Case Reports in

Ophthalmology
Case Rep Ophthalmol 2015;6:191-199

DOI: 10.1159/000434623

c 2015 S. Karger AG, Basel

www.karger.com/cop

Bhandari and Ganesh: Corneal Hydrops in Pellucid Marginal Degeneration: A Case Series

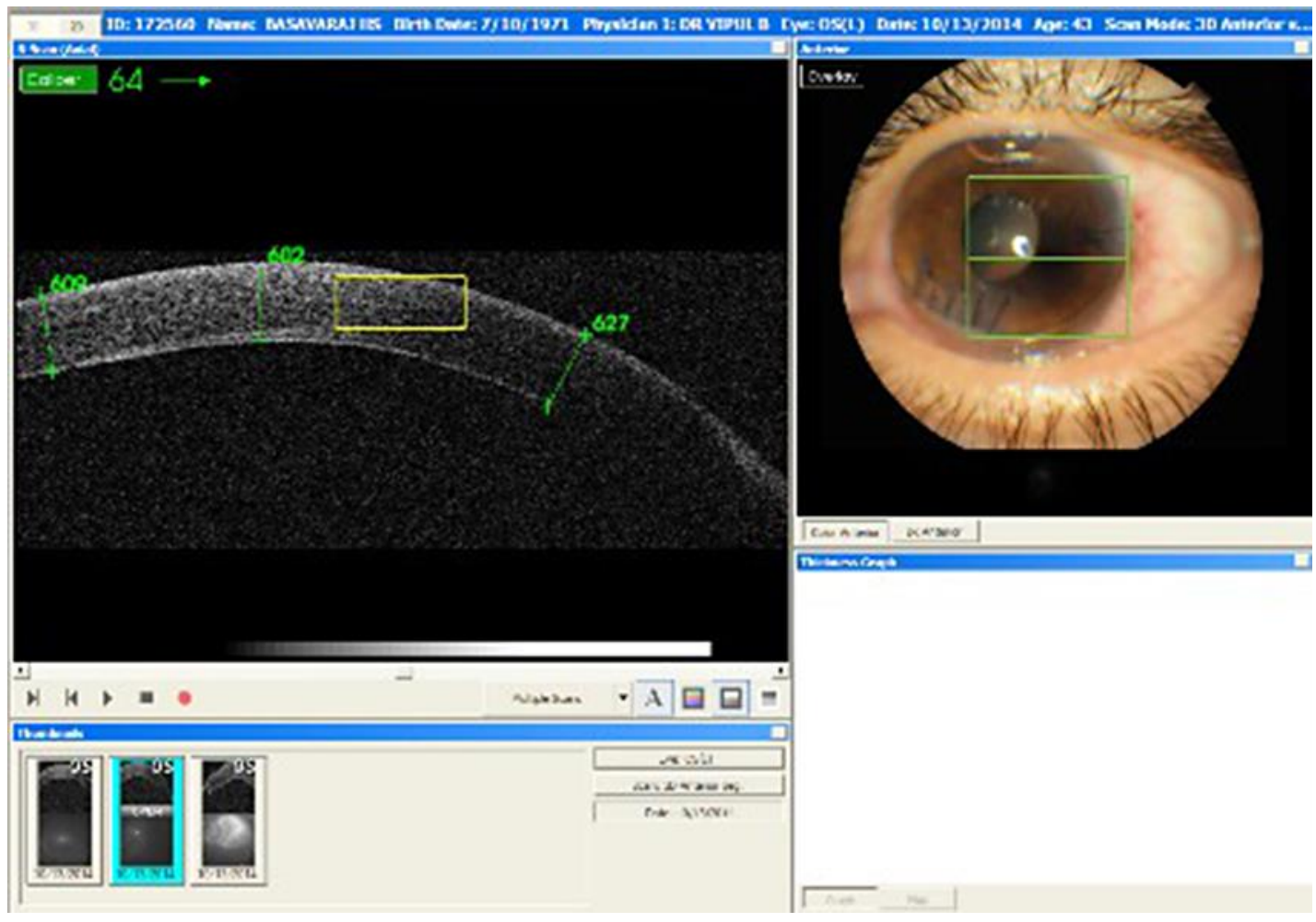

Fig. 5. AS-OCT showing DM attachment. 
Case Reports in

Ophthalmology

\begin{tabular}{l|l}
\hline \multicolumn{2}{l}{ Case Rep Ophthalmol 2015;6:191-199 } \\
\hline DOI: 10.1159/000434623 & $\begin{array}{l}\text { ○ 2015 S. Karger AG, Basel } \\
\text { www.karger.com/cop }\end{array}$ \\
\hline
\end{tabular}

Bhandari and Ganesh: Corneal Hydrops in Pellucid Marginal Degeneration: A Case Series

察 NETHRADHAMA

OCULUS - PENTACAM Belin / Ambrósio Enhanced Ectasia

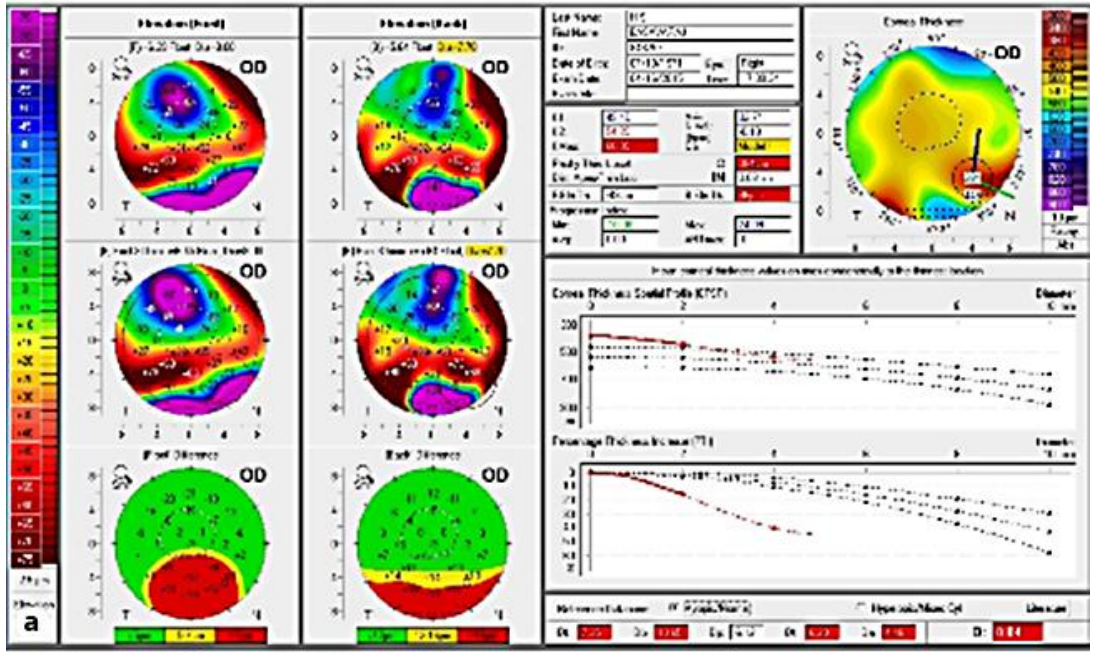

5. NETHRADHAMA

OCULUS - PENTACAM Belin / Ambrósio Enhanced Ectasia

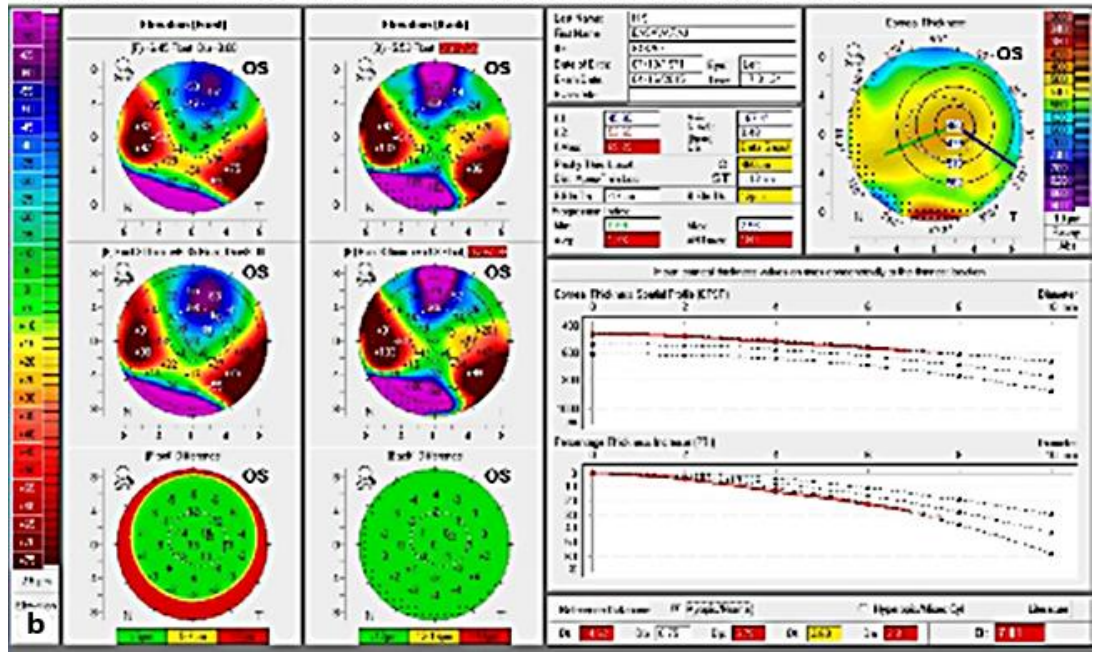

Fig. 6. a, b Pentacam images showing the postoperative maps. 
Case Reports in

Ophthalmology
Case Rep Ophthalmol 2015;6:191-199

DOI: $10.1159 / 000434623$

C 2015 S. Karger AG, Basel

www.karger.com/cop

Bhandari and Ganesh: Corneal Hydrops in Pellucid Marginal Degeneration: A Case Series

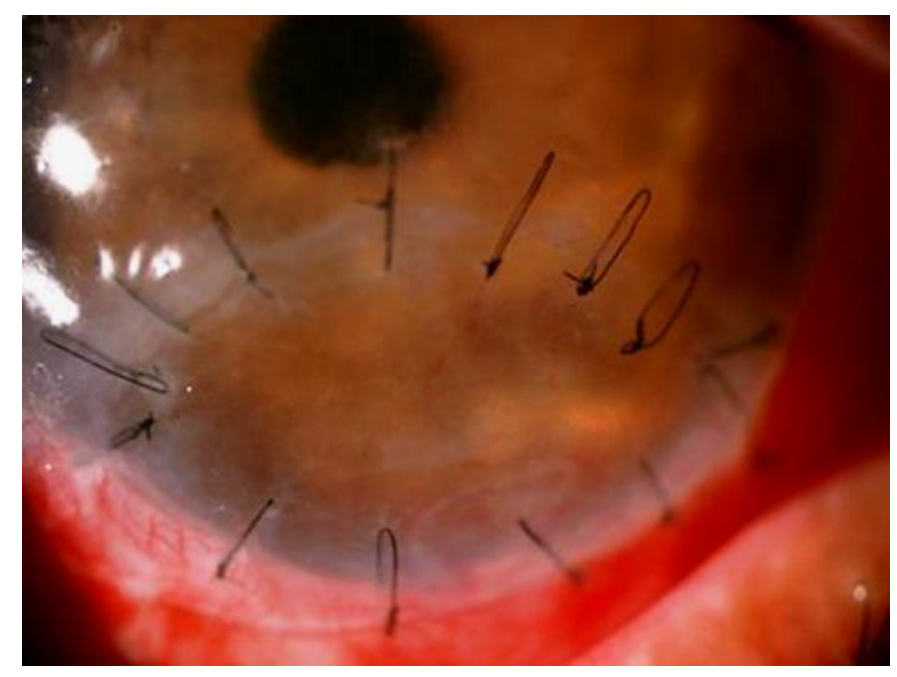

Fig. 7. Lamellar crescentic graft. 